\title{
Lag Screw in Mandibular Plate Technique for Sagittal Splitting Mandibular Fractures
}

\author{
KHALED A. REYAD, M.D. and NIVEEN F. AL MAHMOUDY, M.D. \\ The Department of Plastic, Burn and Maxillofacial Surgery, Faculty of Medicine, Ain Shams University, Cairo, Egypt
}

\begin{abstract}
Background: Mandibular fractures with sagittal splitting and splaying of both the lingual and buccal cortices poses a challenge in their fixation as screws may push the lingual cortex during screw tightening resulting in widening of the mandible.
\end{abstract}

Methods: Screw lagging inside the lower mandibular plate technique may help approximation of the near and far cortices during screw tightening, this was applied for eight cases with mandibular fractures.

Results: The splaying between the two cortices was prevented regaining its normal medullary space width.

Conclusion: Using the screw lagging inside the plate technique may be a safe technique used in mandibular fractures that have cortical splaying.

Key Words: Lag screw - Mandibular - Fractures.

\section{INTRODUCTION}

The use of osteo-synthesis plates and screws offering rigid or semi-rigid fixation is now the usual practice in mandibular fractures. Primary bone healing is possible only in a stable system. Mobility leads to bone resorption and fibrous tissue ingrowth [1,2]. With multiple fractures, the mandible has a tendency to flare outward, which if not corrected and firmly stabilized, results in facial widening and significant malocclusion [3]. Mandibular fractures either combined or single, body or para-symphyseal with sagittal splitting between two cortices, represents a challenge in their reduction and fixation with acceptable bone alignment. Anatomical reduction of fracture is of utmost importance for fracture healing [4]. Splaying of the lingual and buccal cortices of the mandible makes the fixation less stable. Sometimes this splaying is even exaggerated during screw insertion [5].

In this study, screws lagging inside the lower mandibular plate holes were proposed to engage the posterior cortex and compress the two cortices to avoid their splaying.

\section{PATIENTS AND METHODS}

This study was done in Ain Shams University Hospitals from December 2016 to April 2018, patients were selected from trauma patients in the ER with the inclusion criteria of having combined para-symphseal and mandibular body fracture (one on each side) with sagittal splitting between the two cortices, with the exclusion of major polytrauma patients with other systems' affection or major medical comorbidity.

Patients were prepared for open reduction and internal fixation for mandibular fractures with preoperative laboratory and radiological investigations in form of CT facial bones (coronal, axial and three dimensions) and panorex views. All patients were examined for occlusion and mouth opening.

All patients received general anesthesia with nasal intubation. They underwent routine maxillary mandibular fixation as a first step using upper and lower arch bars to adjust the occlusion, then intraoral routine exposure of the fractures was done. Bone was reduced and plates were molded. 5 to 7 holes osteo-synthesis mandibular $2.3 \mathrm{~mm}$ plate on the lower mandibular border on both body and para-symphyseal fractures were placed. In each fracture, the buccal cortex of the splaying segment (i.e. the mandibular segment in between the two fractures) was drilled using drill bit with larger caliber $(2.0 \mathrm{~mm})$ than usually used $(1.8 \mathrm{~mm})$. A $2.0 \mathrm{~mm}$ drill guide is then placed through the hole of the buccal cortex; the lingual cortex is drilled with the drill bit $(1.8 \mathrm{~mm})$. The appropriate screw length was measured by a depth gauge. Meanwhile, in the other lateral segments; screws were inserted into the plate without lagging. At least 2 screws or more was placed in each side. Tightening of the lag screws over the $2.3 \mathrm{~mm}$ plates resulted in compression of the lingual cortex to become nearer to the buccal cortex, thus providing more acceptable bone alignment and more rigid fixation (Fig. 1). 

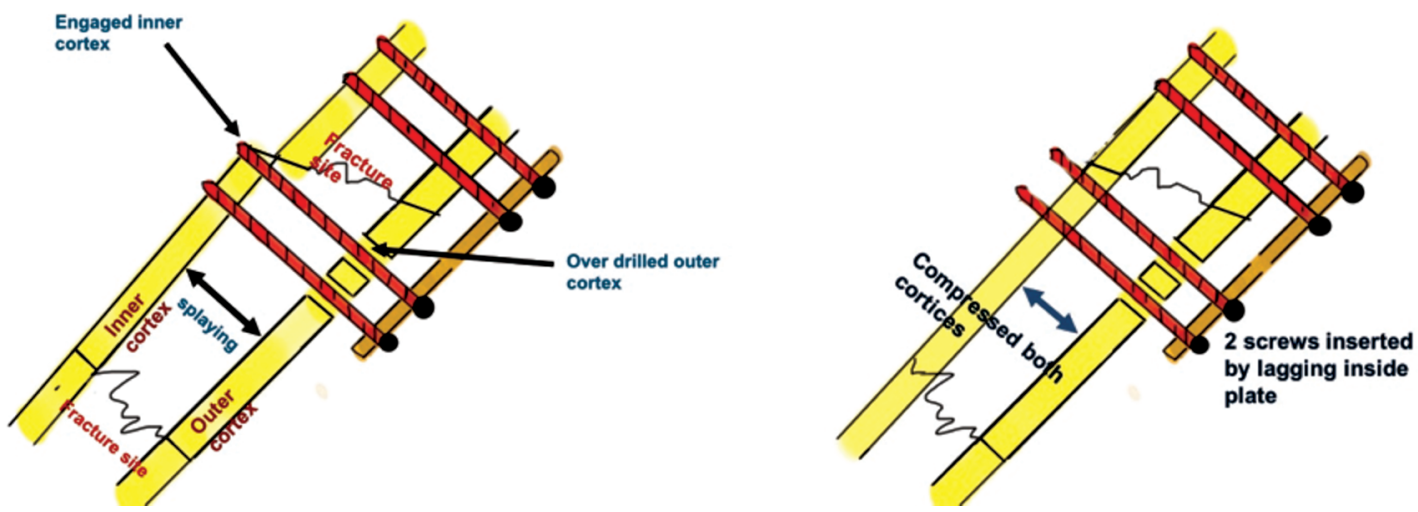

Fig. (1): (Left), Diagram shows drilling of the proximal cortex using drill bit 2.0. This allows engagement of the screws in the lingual cortex only. (Right), Diagram shows that with tightening of the screws, the lingual cortex slides proximally allowing compression of both mandibular cortices.

Mono-cortical 2.0 mini-plates were used as tension bands above the inferior alveolar canal in both the para-symphyseal and body fractures. The arch bar may be left for guided occlusion by elastics. The patients were evaluated by CT facial bones (coronal, axial and three dimension) and panorex views on second day postoperatively. The distance between the lingual and buccal cortices was measured on the CT coronal cuts in centimeters and was compared to pre-operative measurements.

\section{RESULTS}

Eight adult male patients were included in this study with age range 21-47 years (average 36 years), with combined para-symphseal and mandibular body fracture (one on each side) with cortical sagittal splitting. All 8 patients underwent fractures fixation using lagging screws inside mandibular plate. Post-operative coronal and axial CT cuts showed that both mandibular cortices were in good alignment with no splaying (Figs. 2,3). Comparison between the preoperative and postoperative distance between the lingual and buccal mandibular cortices on coronal CT scan cuts was done (Table 1).

All the patients had good postoperative occlusion with no minor or major complications as malunion, or exposure of plates and screws.
Fig. (2): (Left) Pre-operative and (Right) post-operative CT coronal cuts with combined parasymphseal and mandibular body fracture with sagittal splitting and splaying between the lingual and buccal mandibular cortices with obvious reduction of both cortical splaying.

Fig. (3): (Left) Pre-operative three dimension CT cuts showed combined parasymphyseal and mandibular body fracture (Right) post-operative three dimension CT cuts with fixation of both fractures.
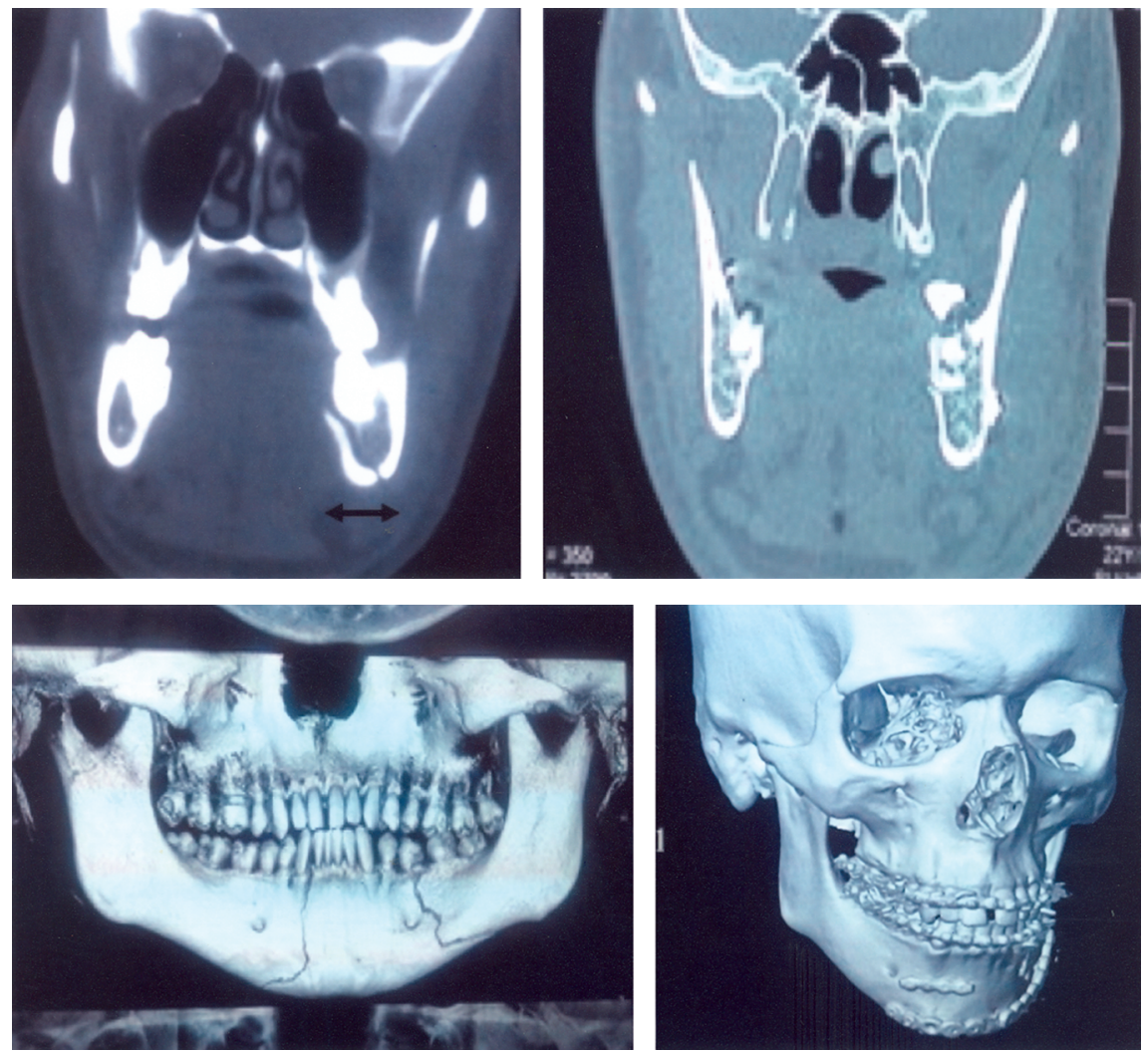
Table (1): Demographic data of the patients.

\begin{tabular}{lcccc}
\hline No. & Age & Pattern of fracture & $\begin{array}{c}\text { Preoperative } \\
\text { distance } \\
\text { between } \\
\text { two cortices } \\
\text { in cms }\end{array}$ & $\begin{array}{c}\text { Postoperative } \\
\text { distance } \\
\text { between } \\
\text { two cortices } \\
\text { in cms }\end{array}$ \\
\hline 1 & 23 & Parasymphseal and body & 2.1 & 1.7 \\
2 & 25 & Parasymphseal and body & 2 & 1.6 \\
3 & 21 & Parasymphseal and body & 2.2 & 1.7 \\
4 & 30 & Parasymphseal and body & 2.1 & 1.8 \\
5 & 28 & Parasymphseal and body & 2 & 1.6 \\
6 & 47 & Parasymphseal and body & 1.8 & 1.5 \\
7 & 45 & Parasymphseal and body & 1.9 & 1.7 \\
8 & 32 & Parasymphseal and body & 2.1 & 1.7 \\
\hline
\end{tabular}

\section{DISCUSSION}

Lag screw and mandibular osteo-synthesis fixation techniques are well known techniques for mandibular fractures fixation [6,7]. The lag screw technique was first introduced to maxillofacial surgery by Brons and Boering in 1970 [8].

The lagging technique was formerly used to treat the symphyseal mandibular fractures or mandibular body fracture with sufficient obliquity $[\mathbf{9 , 1 0}]$, to allow bony compression; However, Lag screws are less useful in the body of the mandible, as the fractures that occur in this region are generally not located in the sagittal plane, with splitting of the buccal and lingual cortices [11].

In the usual practice, both mandibular cortices were approximated with bony holding forceps to promote bony compression, meanwhile plate fixation; however this did not prevent minimal cortical widening [12]. In this study, compression of both lingual and buccal mandibular cortices was achieved through lagging of the screws itself inside the lower mandibular plate. Subsequently the lingual cortex slides over the screw threads proximally allowing compression of both mandibular cortices causing better bone alignment and more rigid fixation.

\section{Conclusion:}

The screws lagging in plate technique is a reliable method to avoid splaying of both the buccal and lingual mandibular cortices, avoiding more splaying and sagittal splitting.

\section{REFERENCES}

1- Miloro M., Ghali G.E., Larsen P.E., et al.: Peterson's principles of oral and maxillofacial surgery, Vol. $3,3^{\text {rd }}$ ed., 2012.

2- Aston S.J., Beasley R.W., Thorne C.H., et al.: Grabb and Smith's Plastic Surgery, 6th ed. Philadelphia: LippincottRaven, 2007.

3- Ellis E. and Tharanon W.: Facial width problems associated with rigid fixation of mandibular fractures. J. Oral Maxillofac. Surg., 50: 87-94, 1992.

4- Sauerbier S., Schön R., Otten J.E., Schmelzeisen R. and Gutwald R.: The development of plate osteosynthesis for the treatment of fractures of the mandibular body - A literature review Journal of Cranio-Maxillofacial Surgery, 36 (5): 251-259, 2008.

5- Ellis $3^{\text {rd }}$ E.: Selection of internal fixation devices in mandibular fracture: How much fixaation is enough? Semin Plast. Surg., 16 (3): 229-241, 2002.

6- Haug R.H., Fattahi R. and Goltz M.: A biomechanical evaluation of mandibular angle fracture plating techniques. J. Oral Maxillofac. Surg., 59: 1199, 2001.

7- Ellis E. III and Miles B.A.: Fractures of the mandible: A technical perspective. Plast. Reconstr. Surg., 120 (7 Suppl. 2): S76-S89, 2007.

8- Brons R. and Boering G.: Fractures of the mandibular body treated by stable internal fixation: A preliminary report. J. Oral Surg., 28: 407, 1970.

9- Forrest C.: Application of minimal access techniques in lag screw fixation of fractures of the anterior mandible. Plast. Reconstr. Surg., 104: 2127-2134, 1994.

10- Niederdellmann H., Schili W., Duker J., et al.: Osteosynthesis of mandibular fractures using lag screws. Int. J. Oral Surg., 5: 117, 1976.

11- Elis III E.: Use of Lag Screws for Fractures of the Mandibular Body J. Oral Maxillofaca. Surg., 54: 1314-1316, 1996.

12- Rogers G.F. and Larry A.S.: Modified Towel-Clamp Technique to Effect Reduction of Displaced Mandible Fractures Plastic \& Reconstructive Surgery, 105 (2): 695697, 2000. 